\title{
ESTIMATION OF DRAG ON SUPERSONIC CONE VARYING NOSE RADIUS AT DIFFERENT AOA
}

\author{
MD. HABEEB ${ }^{1}$, M. SADHIQ ${ }^{2}$, MAMIDI AJAY SAGAR ${ }^{3} \&$ L. SUSHMA ${ }^{4}$ \\ ${ }^{1,2}$ M.Tech (Aerospace Engineering), JNTUH \\ ${ }^{3,4}$ Assistant Professor, Department of Aero, School of Aeronautics, Neemrana
}

\section{ABSTRACT}

A vehicle travelling in supersonic air flow will encounter high molecular disturbance leads to high aerodynamic heating. Its geometrical design produces shock waves resulting to form drag. In decreasing such effects, our studies lead to study various geometric shape of the nose cone. In this, the geometry varies from nose cone to blunt shape. Using CFDFLUENT, Flow simulation is performed to observe leading edge bluntness effect on improvement of less drag during supersonic speeds. Aerodynamic loads are the major factors affecting projectile configuration.

Currently, our research is entirely based on drag reduction by changing nose radius from $\$ 0 D \$$ to $0.1 D, 0.2 D, 0.3 D$ and $0.4 D$ respectively. Overall five designs are generated and they travel in a free stream flow of Mach-2 placing with various Angle of Attacks (AOA) $\left(0^{0}, 4^{0}, 8^{0}\right)$ with an altitude of $25000 \mathrm{~m}$.

Using commercial tool (CFD) as the flow software the model developed is meshed considering supersonic flow properties of Mach-2 and flow is generated over the body. Once after the generation the heat flux and aerodynamic properties will be plotted.

KEYWORDS: CFD, Supersonic, Nose Radius

Received: May 18, 2019; Accepted: Jun 08, 2019; Published: Aug 21, 2020; Paper Id.: IJMPERDJUN2020856

\section{INTRODUCTION}

Supersonic vehicles uses blunt nose during designing and manufacturing so that they can maintain lesser drag for obtaining efficient velocity. Understanding, simulating and anticipating high velocity flow over blunt bodies have an important application in solving engineering problem. Variety of methods have been attempted analytically to shape the nose for penetration.

Huge investigations are carried in this area and finally they brought up with a concept of blunt nose. Navneeth Soori ${ }^{1}$ revealed that blunt body's fallout in drag reduction, thermal flux generated on surface of body is immense ${ }^{1}$. Luther Neal Jr carried out research on AD characteristics of selected cone at an AOA ranging up to $18^{\circ}$ for different degree of bluntness.

These models developed are spherically blunted with a ratio of $h / R=0,0.32$, and 0.65 . A channel of blowdown model was prefer for experimenting about60sec to $90 \mathrm{sec}$, thus results generated were depended on stagnation pressure and AD configuration. Experimental study was conducted on blunted cone nose for M=5.8 by Reginald M. Machell ${ }^{3}$ which had a range over Reynolds number to give significant parameters that governs pressure distribution.

Aerodynamic performances on round leading edges were studied by Wilson F.N. Santos ${ }^{4}$ for a sequence of simulations by parametrically changed radius and angle of attack of the nose. Direct SimulationMonte Carlo 
method given by W.E. Moeckel ${ }^{5}$ conducted experiments on the flow separation along the axis-symmetric body for change in $\mathrm{M}_{\infty}$. He concludes by optimizing drag as lower with a tip-rod projection, which is about3 times the nose radius. Yasumasa Watanabe studied aerodynamic characteristics of air-breathing blunt nose configuration during hypersonic speeds. This approach is the most convincing on reduction of drag. The results found 5\% drag reduction for air breathing designs but lift to drag ratio remains unaffected. Results generated from these investigations are for free flight for $\mathrm{M}_{\infty}=0.6$ to 2.3. Harvey A.Wallskog and Roger G. Hart ${ }^{7}$ even the minor change in degree of spherical bluntness leads to total drag reduction for Mach no. range from 1 to 1.4 during parabolic path.

\section{NUMERICAL STUDY}

The turbulence model used in the present computational study is the standard $k-\pi$ model which implies two PDE to calculate velocity and distance scale of turbulence. A standard enclosure function described by launders and Spalding is used in our calculations.

$$
\begin{aligned}
& k_{\mathrm{z}}=\alpha\left(\frac{k^{2}}{\varepsilon} k_{x}\right)_{x}-\varepsilon \\
& \varepsilon_{t}=\beta\left(\frac{k^{2}}{\varepsilon} k_{x}\right)_{\varepsilon}-\gamma^{2} \frac{\varepsilon^{2}}{k}
\end{aligned}
$$

Where $\mathrm{k}=\mathrm{k}(\mathrm{x}, \mathrm{t})$ it the turbulent kinetic energy $\varepsilon=\varepsilon(\mathrm{xt})$ is the rate of dissipation of turbulent energy and $\alpha, \beta$ and $\gamma$ are positive constrains.

Even though, the true development of the model is often credited to jones and Launder, it should be noted that (KE) sometimes refer to as the $b-\varepsilon$ model, in acknowledgement of Kolmogorov's. Original insight and relationship between the variables used: $b=\frac{2}{3} k \mathrm{~b}$ where $\omega$ and $b$ are proportional to $s$.

The nose factor, $\mathrm{N}$, is a parameter commonly used in penetration mechanics to quantify the penetration-drag characteristics of a nose geometry during penetration of hard targets. It is a non-dimensional quantity that is only dependent on the geometry of the nose shape. In penetration mechanics, it is common to approach the problem by ignoring the friction forces acting on a perpetrator and assume the pressure forces are the primary source of penetration drag. Due to this assumption, the penetration-drag coefficient also becomes a function independent of everything except nose geometry. This also causes the nose factor and penetration-drag coefficient to differ by a constant multiplier. An analysis of the case for pressure-dependent friction has been given by Jones and Rule [2000], but will not be considered in this study.

The following equations detail the relationship between the nose factor, the penetration drag coefficient, and the coefficient of pressure, $\mathrm{Cp}$. The coefficient of pressure has been approximated, using an equation similar to Newton's theory which applies to hypersonic flows, to apply to a slender body during penetration. The expression for the $\mathrm{Cp}$ is as follows:

$$
c_{p}=\frac{2 y^{2}}{1+y^{2}}
$$

Using this coefficient of pressure, and neglecting the viscous forces, the drag force can be found

$$
\text { Using }
$$




$$
D_{p}=\int_{0}^{b} C_{p} y d x
$$

To lead to the definition of the nose factor, an intermediate step, ID is defined as a function of the nose geometry:

$$
I_{d}=\int_{0}^{b} \frac{2 y y^{2}}{1+y^{2}} d x
$$

Finally the nose factor is defined as:

$$
N=2 \alpha^{2} \int_{0}^{1} \frac{z x^{3}}{1+\alpha^{2} x^{2}} d \zeta
$$

As was discussed earlier the expression for nose factor is solely dependent on the nose geometry. This allows the nose factor to be directly related to penetration-drag coefficient and means the minimum nose factor, N, also corresponds to the nose that would experience the least resistance during penetration. Once again, it should be emphasized that this penetration drag coefficient, Dp, is defined only using the form drag, drag due to the pressure related forces, without taking into account viscous effects. The penetration-drag coefficient used in penetration mechanics differs from the drag coefficient, CD, used in fluid mechanics. The aerodynamic drag coefficient of an object is dependent on Reynolds and Mach numbers. However if Newton's theory, the appropriate values for dynamic pressure (q) and aerodynamic drag coefficient $(\mathrm{CD})$ is applied which describes penetration drag, Dp, becomes the equation for aerodynamic drag, D. This leads to the conclusion that minimizing nose factor will also minimize an objects aerodynamic drag.

\section{GEOMETRIC MODELLING}

A 2D rectangular mesh with $400 \mathrm{~mm} \times 200 \mathrm{~mm}$ cross section is selected. The base diameter of a wedge is selected as $50 \mathrm{mmand}$ the geometric length varies by change in cone angle and nose radius. Thus geometry is segregated into a number of species using face split tool to give fine mesh over the geometry.

A 2-D planar symmetric model is developed using ICEM-CFD. The geometry adopted in present study is a nose cone with increase in radius from 0 to 20 with several of 5 in between. Five designs were developed due to increase in radius and these designs varied from sharp nose cone to blunt nose cone, whereas the diameter of the cone remains same but as the increase in radius length of the cone decreases. A $2 \mathrm{D}$ wedge inside a rectangular enclosure with $400 \mathrm{~mm} \mathrm{x}$ $200 \mathrm{~mm}$ cross section is considered. The base diameter of the wedge is $50 \mathrm{~mm}$ and the length of the wedge varies with cone angle and nose radius. The geometry has been divided into a number of faces using face split tool. This helps in giving a finer mesh in the area which is of interest in our study.

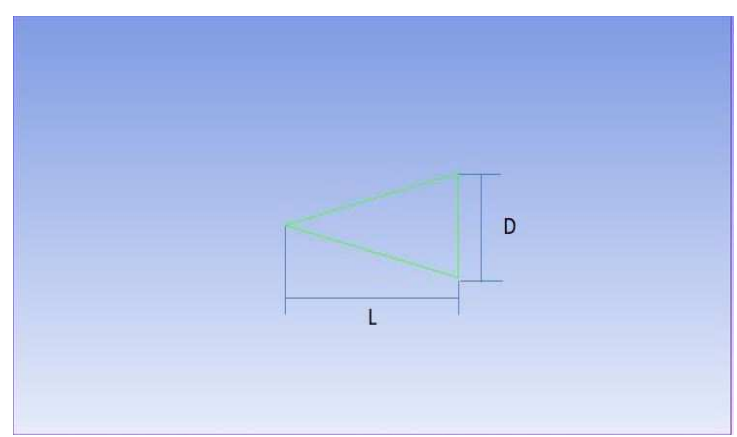

Figure 1: Nose Cone with Radius = 0D. 


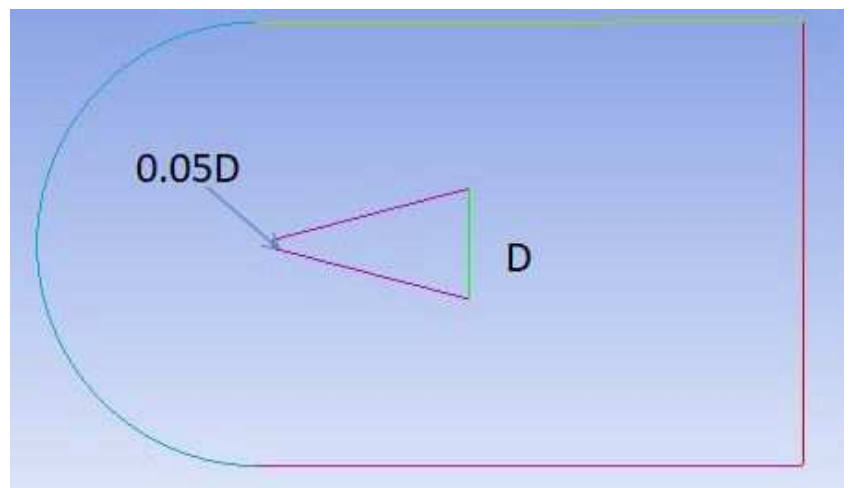

Figure 2: Nose Cone with Radius = 0.1D.

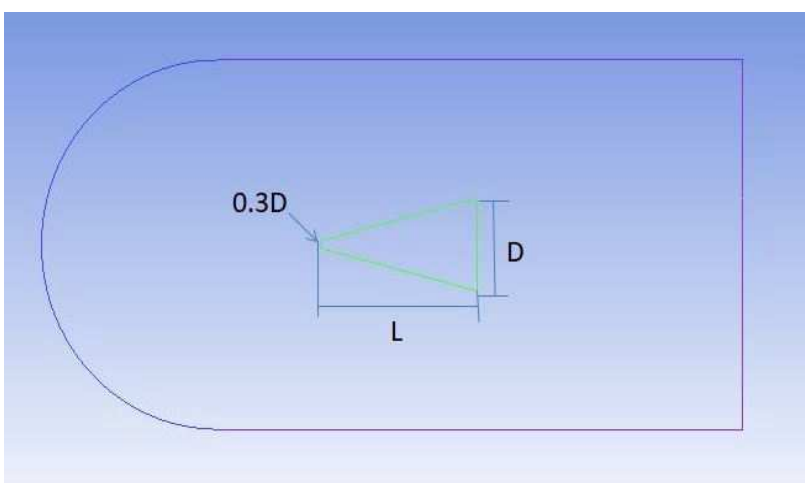

Figure 3: Nose Cone with Radius $=0.2 \mathrm{D}$.

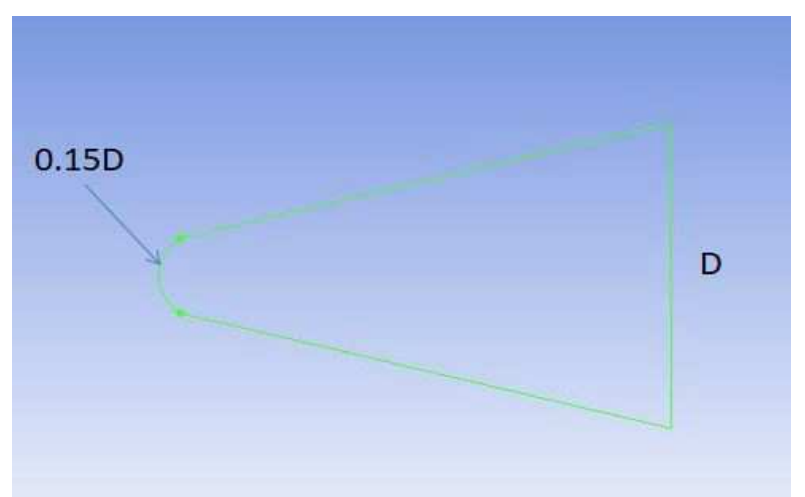

Figure 4: Nose Cone with Radius $=0.3 \mathrm{D}$.

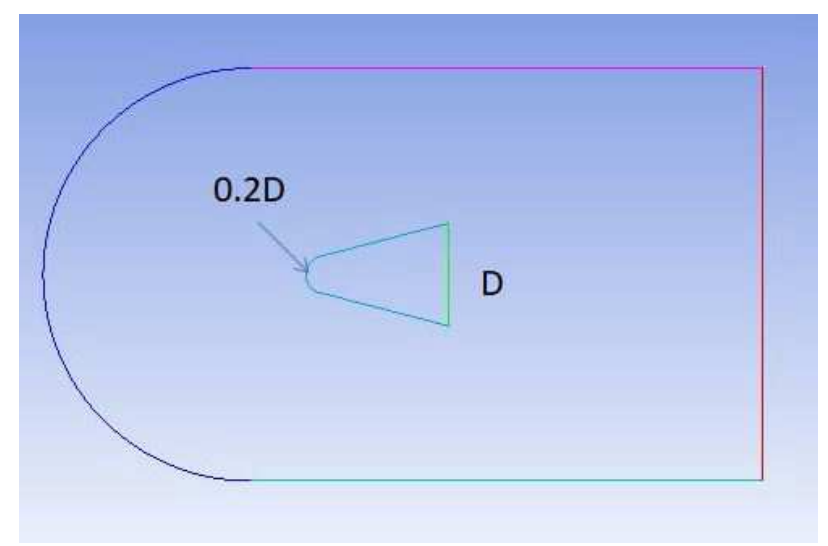

Figure 5: Nose Cone with Radius $=0.4 \mathrm{D}$. 


\section{MESHING}

A structured mesh is used in order to achieve accurate results. The meshing is done symmetrical about $\mathrm{x}$-axis. The number of elements on each side can be changed using edge sizing technique. The entire geometry has been divided into 50000 to 80000 elements where the minimum size of an element is $0: 2 \mathrm{~mm}$ and maximum size of the element is $22 \mathrm{~mm}$. The mesh near the nose is made finer and the area ahead of the shock is left course in order to reduce the calculation time.

\section{Boundary Conditions}

Pressure far field is assigned to inlet and wall for the model; whereas pressure outlet for exit flow. Stationary wall condition is assigned for geometry. Pressure far field containing Mach number, flow direction, temperature, static pressure, and turbulence parameters is assigned which were obtained from free stream conditions that are given for an altitude of $25000 \mathrm{~m}$ above sea level.

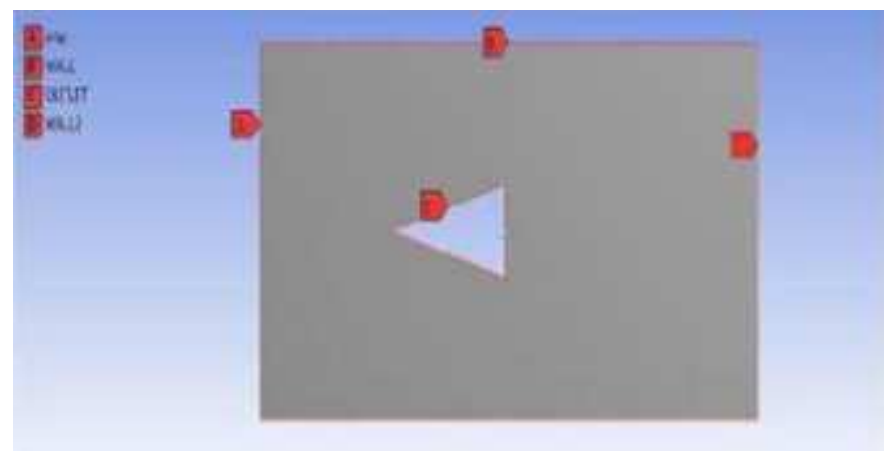

Figure 6: Boundary Conditions.

\section{Free Stream Conditions}

$$
\begin{aligned}
& \mathrm{M}_{1}=2 \\
& \text { Altitude (meters) }=25000 \\
& \text { Temperature }(\mathrm{K})=221.65 \\
& \text { Pressure }(\mathrm{Pa})=2.51102 \mathrm{E}+3 \\
& \text { Density }\left(\mathrm{Kg} / \mathrm{m}^{3}\right)=3.94658 \mathrm{E}-2 \\
& \text { Viscosity }\left(\mathrm{N}-\mathrm{s} / \mathrm{m}^{2}\right)=1.46044 \mathrm{E}-5
\end{aligned}
$$

\section{METHODOLOGY}

ANSYS Fluent CFD solver is used for flow field analysis. Fluent is a Finite Volume solver and using density based method because of supersonic flow. Flow field is solved for Continuity, Momentum, Energy and turbulence equations throughout domain. It is solved for number of iterations till convergence is attained. 


\section{RESULTS AND DISCUSSIONS}
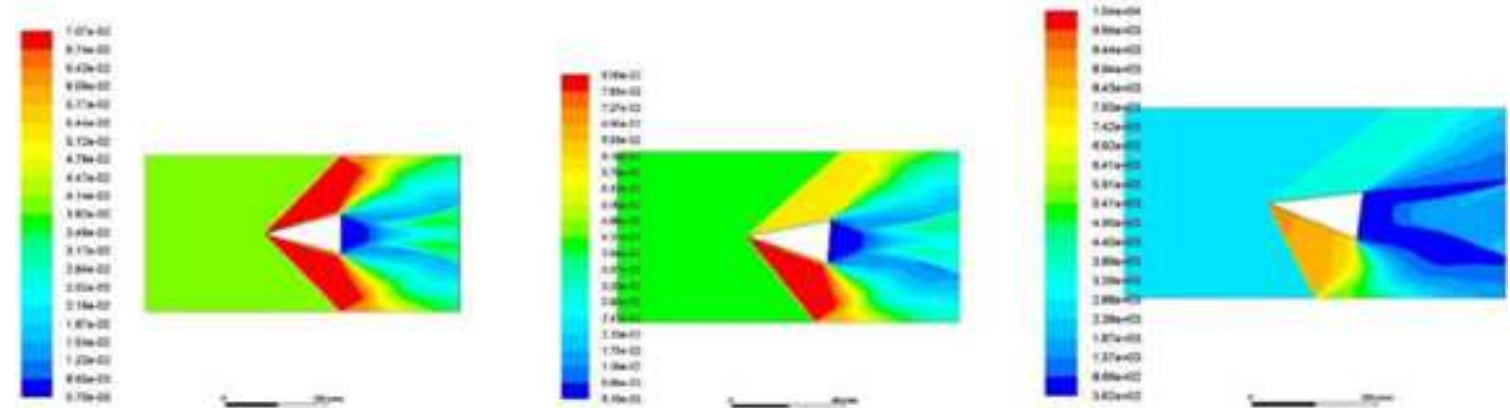

Figure 7: Density Contours for Cone Nose Radius = 0 .
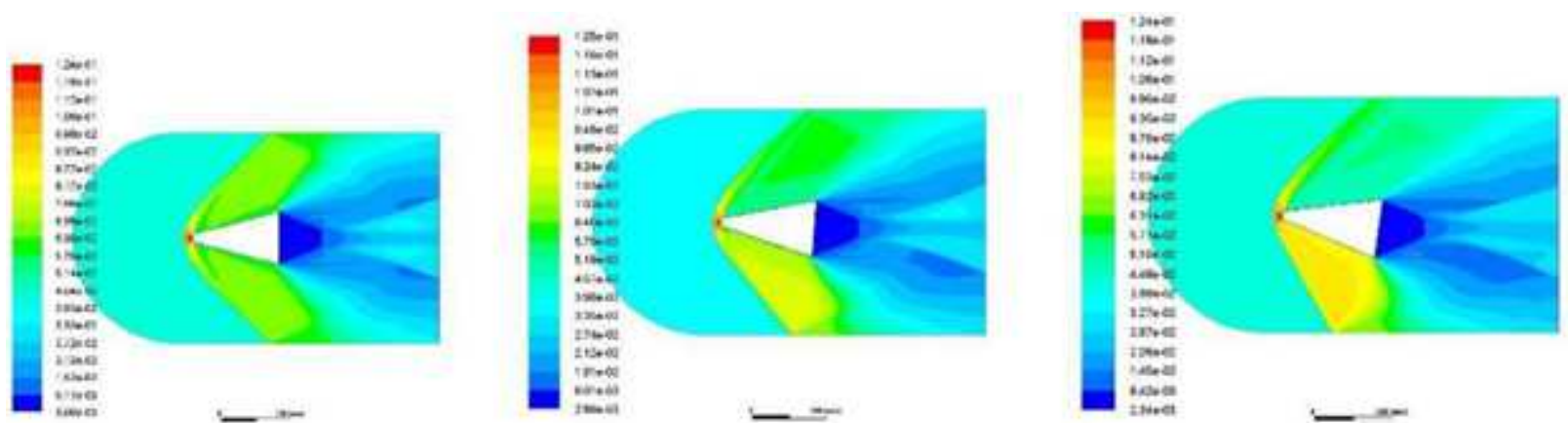

Figure 8: Density Contours for Cone Nose Radius = 10 .
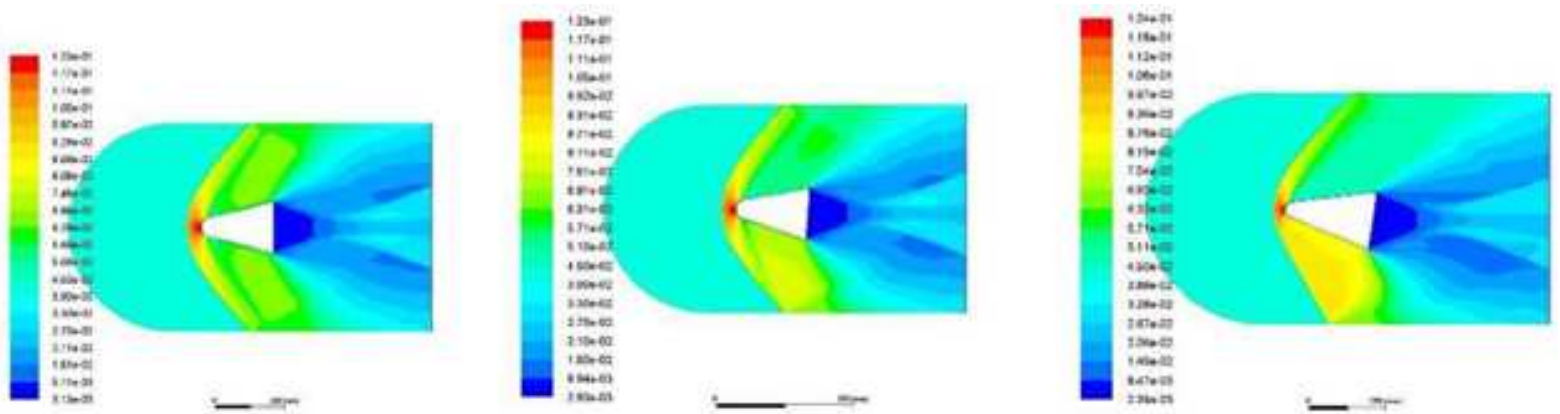

Figure 9: Density Contours Cone Nose Radius = 20 .

The above picture shows the density contours occurred for all the blunt cones here we observe as the AOA increases maximum flow occurred in the bottom wall. Shock stand-off distance enlarged accordingly by rise in nose radius.
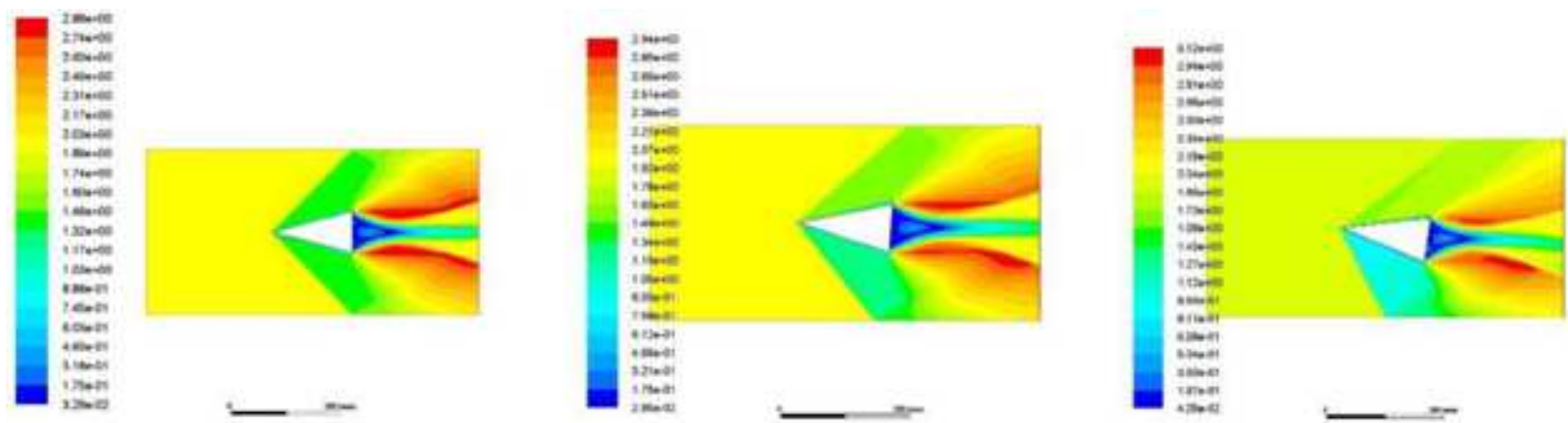

Figure 10: Mach Contours for Cone Nose Radius = 0 . 

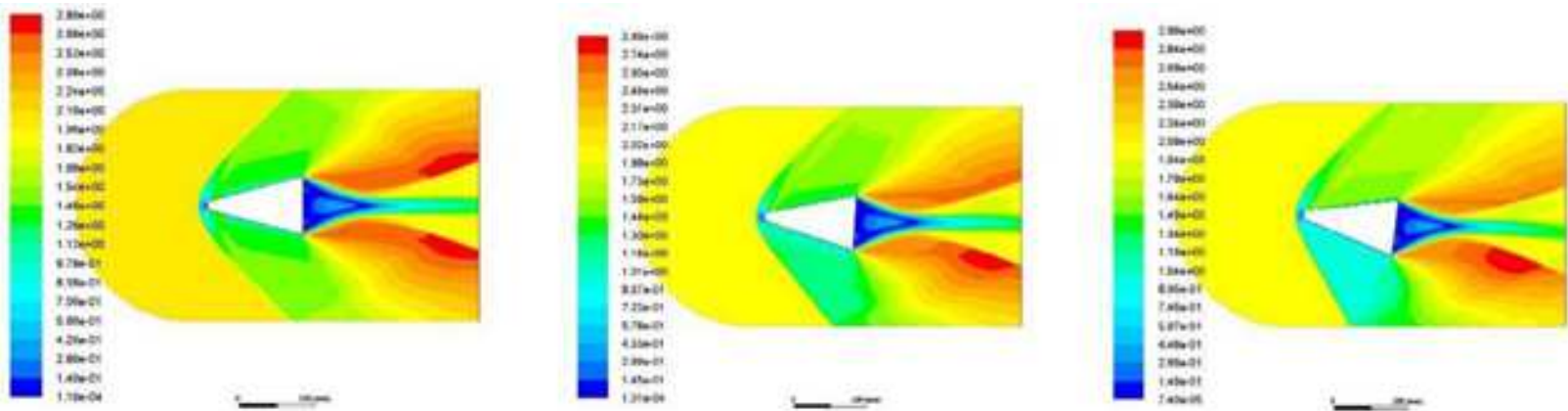

Figure 11: Mach Contours for Cone Nose Radius = 10.
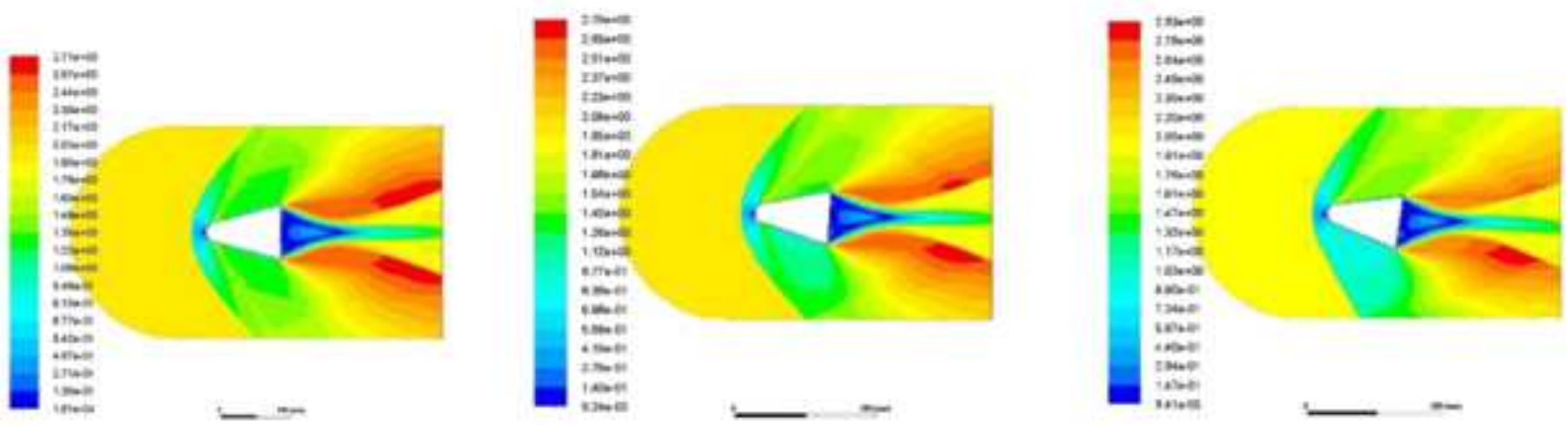

Figure 12: Mach Contours for Cone Nose Radius = 20.

Here we observed that as the increase in radius, decreases in bluntness. Mach number raised that states drag is reduced by reducing the bluntness.
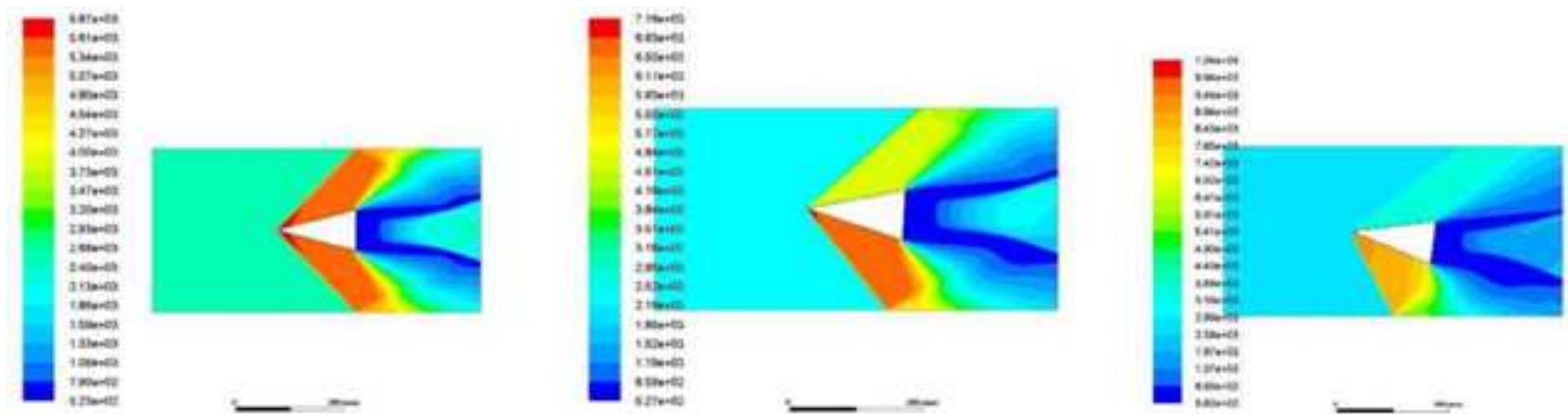

Figure 13: Pressure Contours for Cone Nose Radius $=0$.
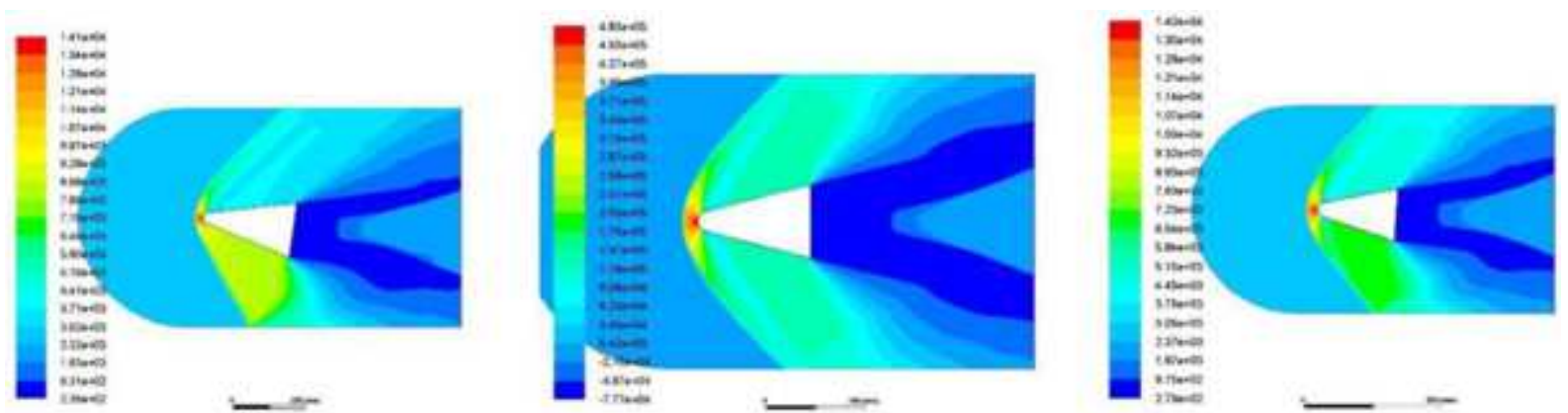

Figure 14: Pressure Contours for Cone Nose Radius = 10 . 

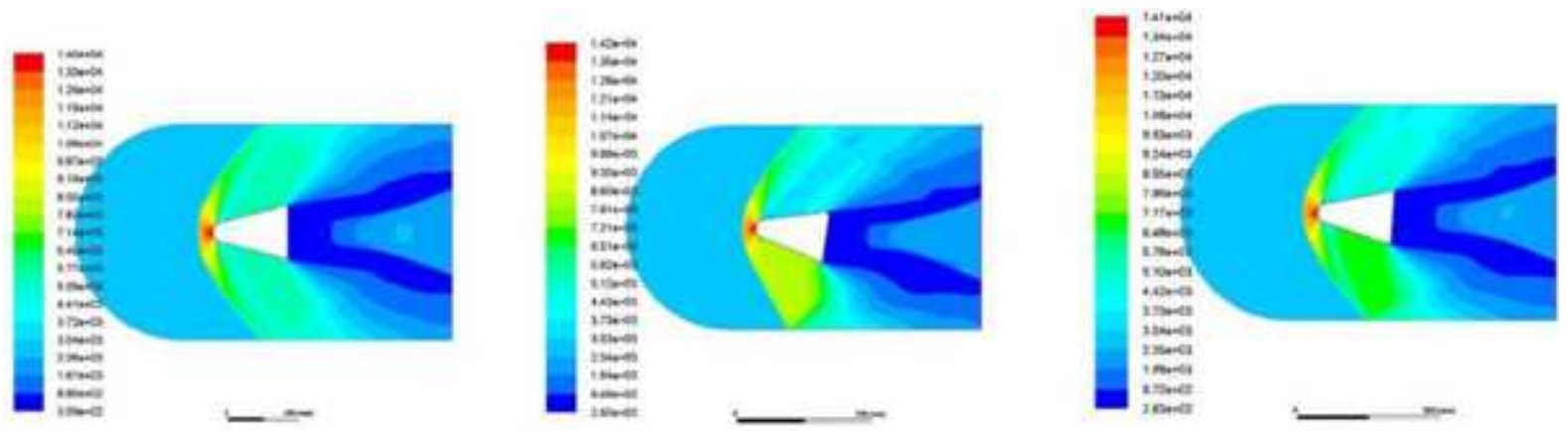

Figure 15: Pressure Contours for Cone Nose Radius = 20 .
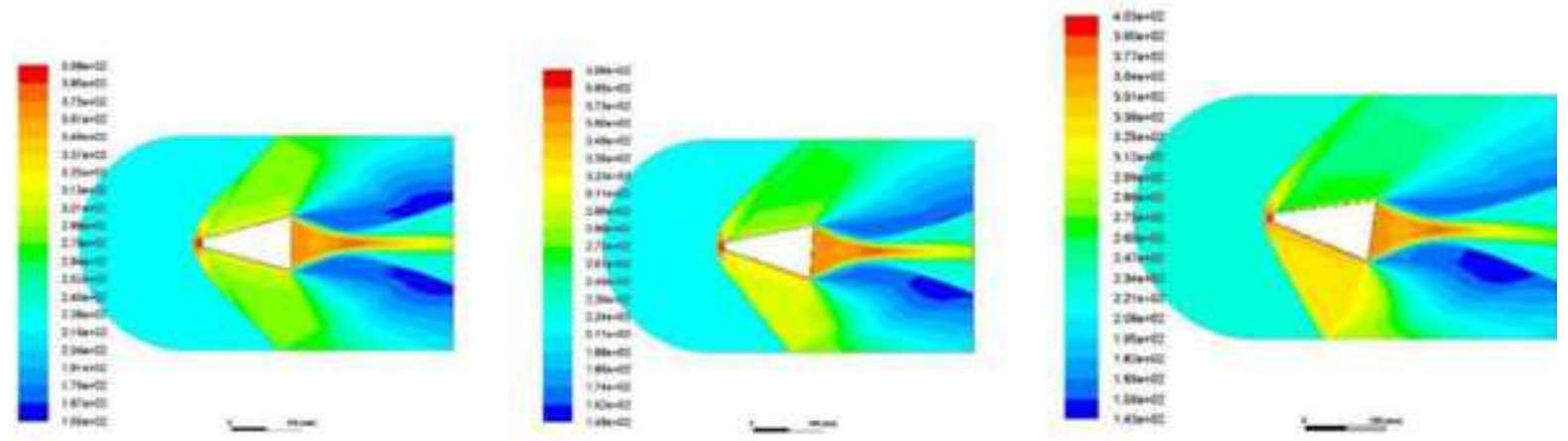

Figure 16: Temperature Contours for Nose Radius=0.
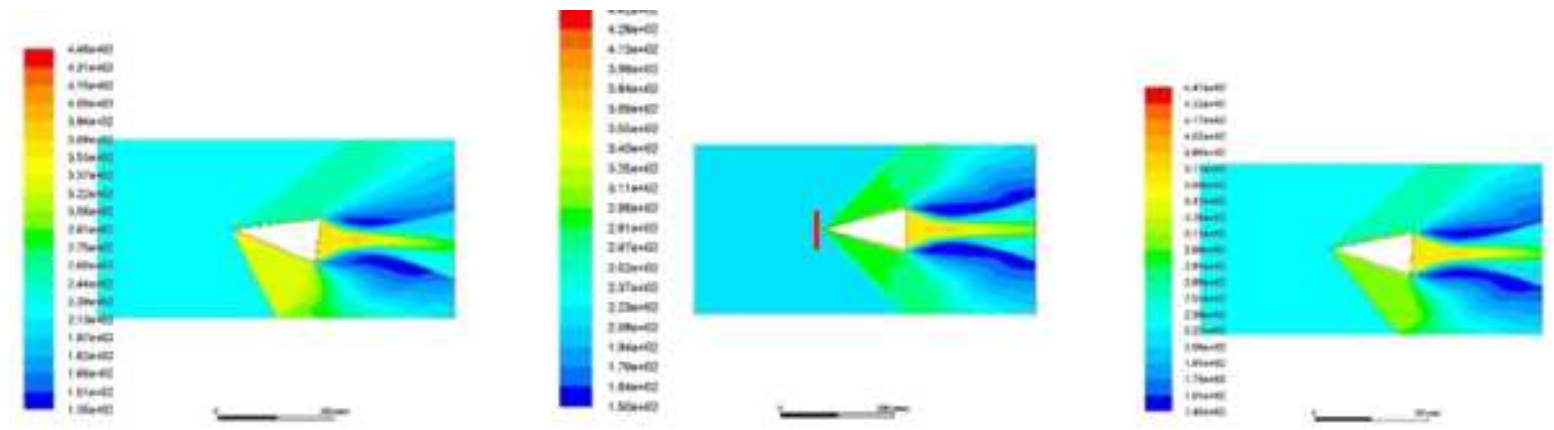

Figure 17: Temperature Contours for Nose Radius=10.
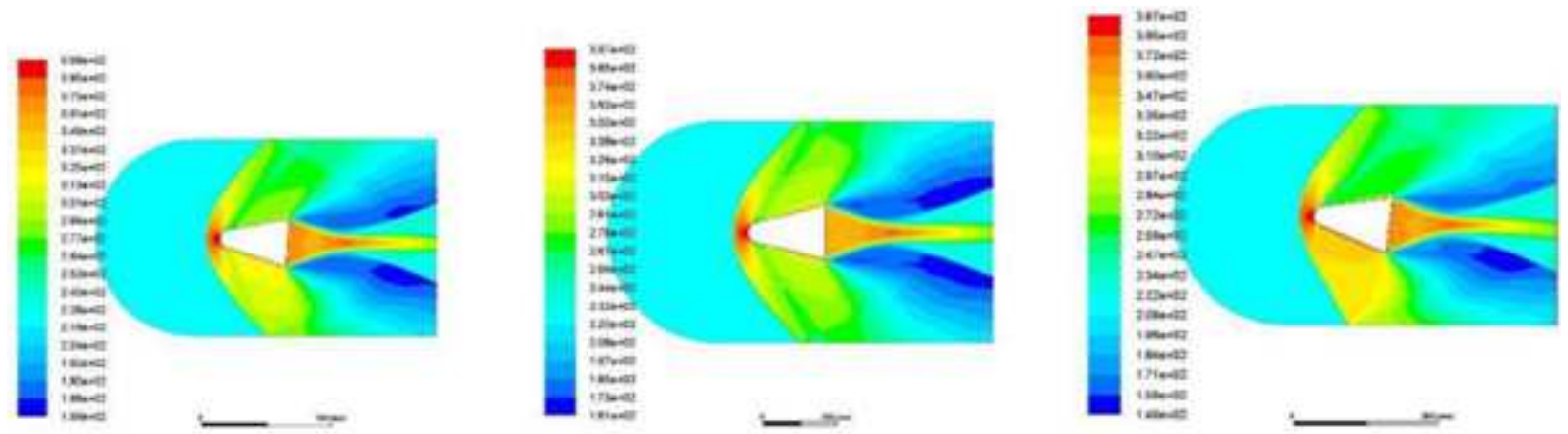

Figure 18: Temperature Contours for Nose Radius=20.

Here we observed as the bluntness increases temperature decreases. It also shows as the AOA increases temperature decreases which means heat flux decreases by increasing bluntness of nose radius and AOA(angle of attack). 


\section{CONCLUSIONS}

Our study on increasing Nose cone radius with a $0.5 \mathrm{D}$ variation concludes by studying the dragoriginated by the nose cones during supersonic speed. As the cone radius increases the drag also increases. We observed around $423 \mathrm{~N}$ of drag is generated for sharp cone. As the nose radius increases a medium of $25 \mathrm{~N}$. This increase continued to further and finally 540 N0s was obtained for Nose radius $=0.2 \mathrm{D}$. During re-entry increase in bluntness will help more than a sharp nose. These reading are plotted and given in the following graph shown in below figure.

Even increase in Angle of Attack (AOA) also affected in increasing the drag. In the fallowing we observe that drag generated has increased by increase in AOA which started from around $450 \mathrm{~N}$ and ended nearly up to $650 \mathrm{~N}$ during $\mathrm{AOA}=0^{\circ}$. When the AOA is increased to $\mathrm{AOA}=4^{\circ}$ the drag generation also increased slightly somewhere from $460 \mathrm{~N}$ and ending with $570 \mathrm{~N}$. When further $\mathrm{AOA}$ is increased to $\mathrm{AOA}=8^{\circ}$ a huge drag generation is observed. It was finally a representation is done by showing the overall percentage of drag generated by all the define designs and found that sharp cone gave best results on reduction of drag it was about $18 \%$ and highest drag was recorded for Blunt nose radius $=0.2 \mathrm{D}$ was about $22 \%$.

Whereas bluntness yields in decrease in temperature to as low as possible, So increase in bluntness will decrease the temperature. This helps mostly during re-entry conditions.

\section{Drag generated in Newton's}

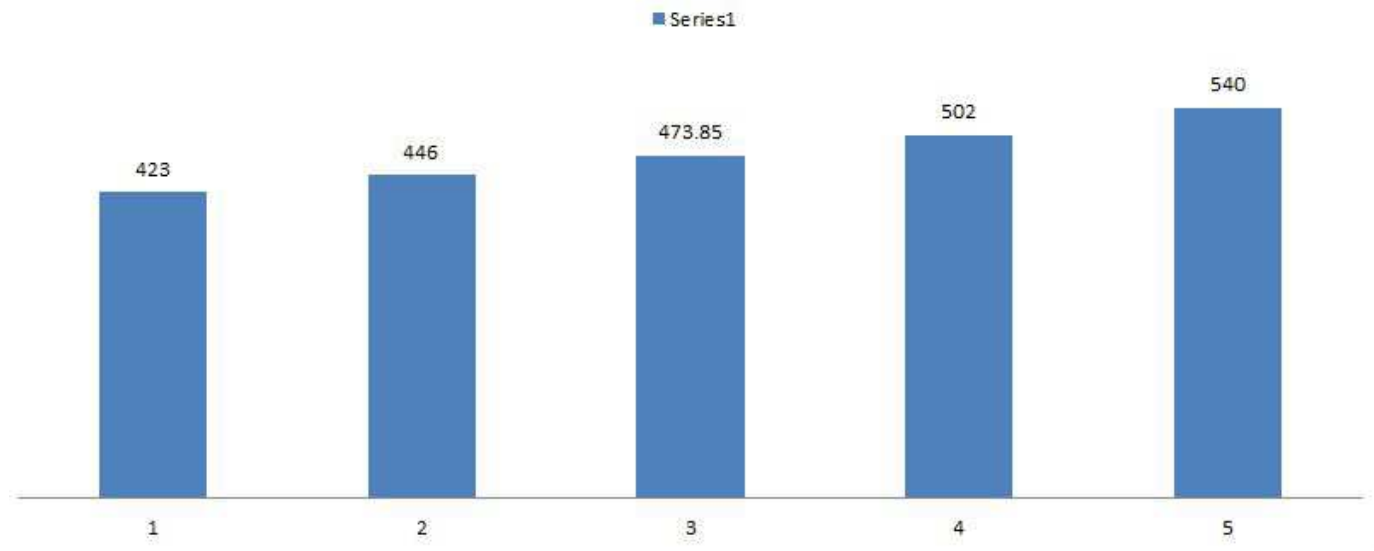

Figure 19: Drag Originated by Increase in Nose Cone Radius.

\section{REFERENCES}

1. NavneethSoori, Numerical study of heat flux developed on an aero-spike structure in hypersonic flow, Aerospace Conference, 2015 IEEE, pp. 1-7.

2. Jr. Luther Nea, Aerodynamic characteristics at $M \infty=6.77$ of a 90 cone configuration, including and excluding spherical bodies, at angles of attack up to 180fordifferentdegree of nose blunt, 1963.

3. R. M. Machell and W. T. O. Bryant, Experimental setup on Flow over BluntNosed Cones at a Mach number of 5.8", 1956.

4. Alavala, Chennakesava R. "FEM analysis of single point incremental forming process and validation with grid-based experimental deformation analysis." International Journal of Mechanical Engineering 5.5 (2016): 1-6.

5. F. N. Wilson. Santos, Nose radius influence on drag and lift of round leading edges inhypersonic flow p. 11,Nov 2007.

6. W.E. Moeckel, Flow separation on axi-symmetric blunt body at M $\infty=1.76$ to 2.10,Cleveland,Ohio, Dec, 1951. 
7. Yasumasa Watanabe, Kojiro Suzuki and EthirajanRathakrishnan, AD characteristics of air breathing blunt nose during hypersonic flow, University of Tokyo, Kashiwa, Chiba, Japan.

8. Akil, Loumani, Belarbi Fatima, and Bensoltane Ahmed. "Enumeration, Isolation And Identification Phenotypic Thermophile Lactic Acid Bacteria Isolated From Different Fermented Milk Collected In Algeria. International Journal of Applied and Natural Sciences (IJANS)5. 5, Aug - Sep 2016; 53-62

9. A. Harvey. Wallskog and G. Roger Hart, Investigation of the drag of blunt nosed bodies of revolution in free flight at Mœ from 0.6 to 2.3, V. A. Langley Field, 1953.

10. Mankar, D. S., and P. M. Khodake. "Residual Stress Produced After Machining in Mechanical Components and its Effects on Fatigue Life: a State of Art." International Journal of Mechanical and Production Engineering Research and Development (IJMPERD) 5.1 (2015): 1-10.

11. G. Gopala Krishnan, J. Akhil and S. R. Nagaraja, Heat Transfer simulation on Re-entry Vehicle with Spikes, 1st IHMTC2015, Thiruvannanthapuram, India, December 2015.

12. Malagi, Ravindra R., Sanjeevkumar R. Chougula, and Ravira J. Shetty. "Prediction of cutting force in turning of ti-6al-4v under minimum quantity lubrication (Mql) using response surface model and fuzzy logic model." International Journal of Mechanical and Production Engineering Research and Development 8.6 (2018): 263-274.

13. N. Sreekanth, J. Akhil and S.R. Nagaraja 2016, Analytical design of Secondary Spike on Blunt Head, IJST, Vol. 9(45), December 2016.

\section{AUTHOR DATA}

\section{First Author Data}

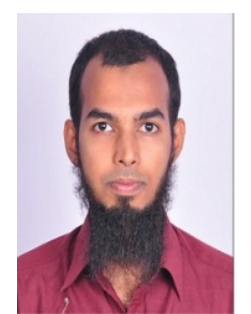

Mr. MOHAMMAD HABEEB has completed B.Tech in Mechanical Engineering and M. Tech Aerospace Engineering from JNTUH. His Areas of interest are Manufacturing, engineering drawing, production drawing, automobile, Aerodynamics.

\section{Second Author Data}

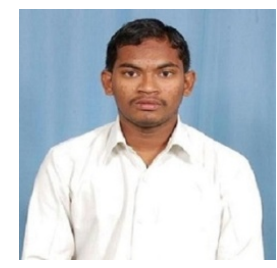

Mr MAMIDI AJAY SAGAR has completed B Tech in Aeronautical Engineering and M Tech in Aerospace Engineering from MRCET/JNTUH, and currently working as Assistant professor in School of Aeronautics, Neemrana, Rajasthan. His area of interest is High Speed and Experimental Aerodynamics. He had worked in DRDL as a Contract Engineer for one year. 


\section{Third Author Data}

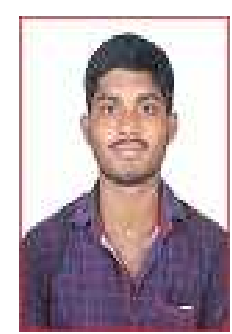

Mr. M. Sadhiq has completed B.Tech in Aeronautical Engineering and M. Tech Aerospace Engineering from MRCET/JNTUH. His areas of interest are Aerodynamics and Computational Fluid Dynamics.

\section{Fourth Author Data}

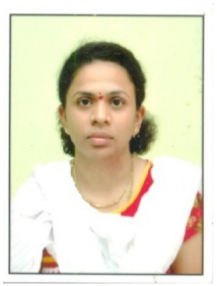

Ms L. Sushma has completed her B.Tech and M.Tech from JNTUH in Aeronautical Engineering. She has 14 years of experience in teaching and industry. Presently she is persuing $\mathrm{PhD}$ in Mechanical Engineering from JNTUH. She has published and presented 7 papers in International Journals, International and National Conferences. She has achieved gold certificate for presenting best paper in ICEMS 2016. Her areas of interest are High speed propulsion and Computational Fluid Dynamics. 

